\title{
In vitro inhalation bioaccessibility of phthalate esters and alternative plasticisers present in indoor dust using artificial lung fluids
}

Article

Accepted Version

Kademoglou, K., Giovanoulis, G., Palm-Cousins, A., PadillaSanchez, J. A., Magnér, J., de Wit, C. A. and Collins, C. D. (2018) In vitro inhalation bioaccessibility of phthalate esters and alternative plasticisers present in indoor dust using artificial lung fluids. Environmental Science and Technology Letters, 5 (6). pp. 329-334. ISSN 2328-8930 doi: https://doi.org/10.1021/acs.estlett.8b00113 Available at https://centaur.reading.ac.uk/82313/

It is advisable to refer to the publisher's version if you intend to cite from the work. See Guidance on citing.

To link to this article DOI: http://dx.doi.org/10.1021/acs.estlett.8b00113

Publisher: American Chemical Society

All outputs in CentAUR are protected by Intellectual Property Rights law, including copyright law. Copyright and IPR is retained by the creators or other copyright holders. Terms and conditions for use of this material are defined in the End User Agreement. 


\section{www.reading.ac.uk/centaur}

\section{CentAUR}

Central Archive at the University of Reading

Reading's research outputs online 


\section{$1 \quad$ Graphical abstract}

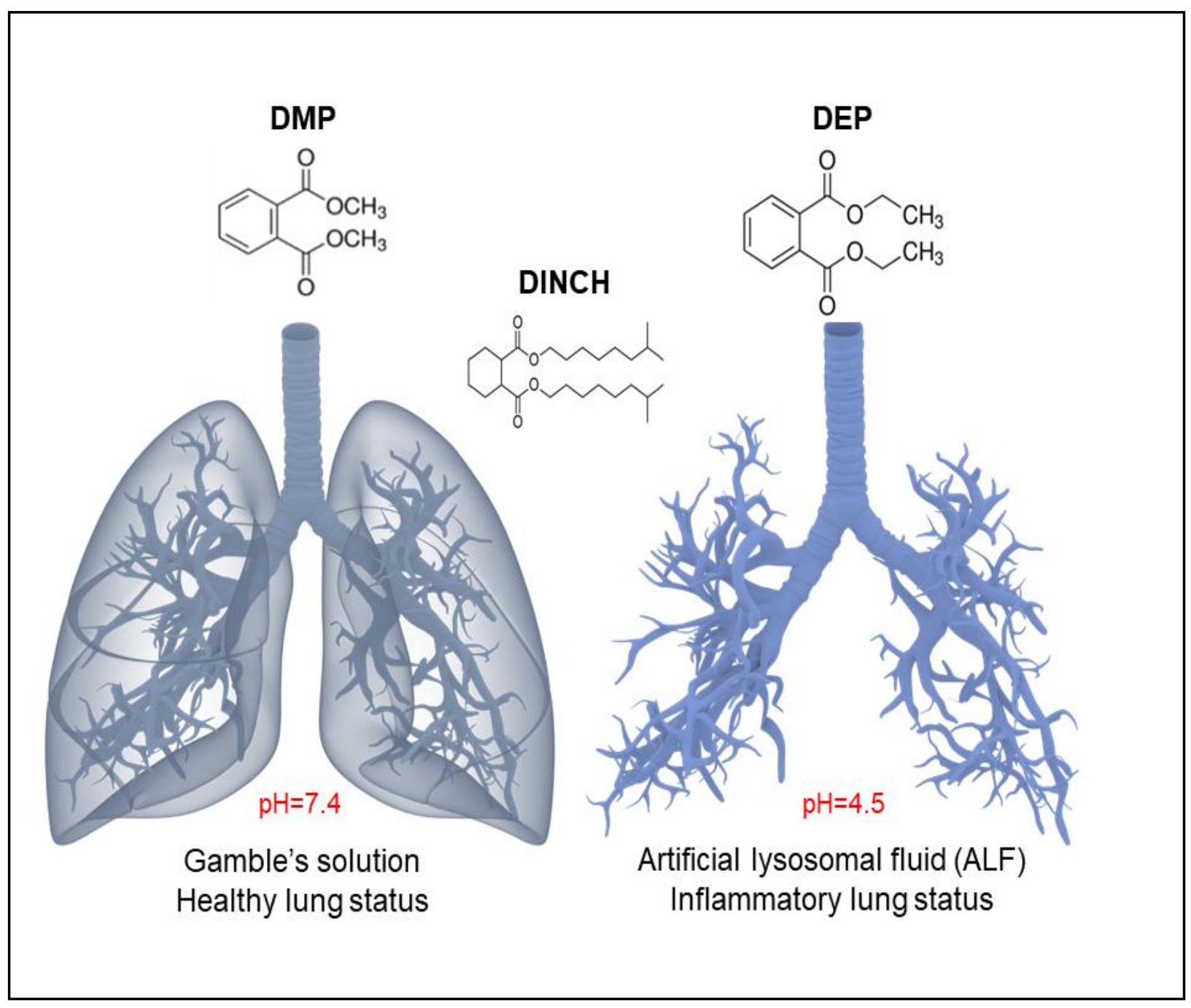




\section{$3 \quad$ Highlights}

4 - First study on in vitro inhalation bioaccessibility of organics from house dust

5

- Gamble's solution and artificial lung fluid were used as pulmonary surrogate media

6

- $\quad$ DMP and DEP were $>75 \%$ bioaccessible in both lung media

7 - Alterative plasticisers DINCH and DEHT were $<5 \%$ bioaccessible

- Inhalation bioaccessibility was highly influenced by hydrophobicity 
10 In vitro inhalation bioaccessibility of phthalate esters and alternative plasticisers present in 11 indoor dust using artificial lung fluids

12 Katerina Kademoglou ${ }^{\mathrm{a}, \mathrm{b} *}$, Georgios Giovanoulis ${ }^{\mathrm{c}, \mathrm{d}}$, Anna Palm-Cousins ${ }^{\mathrm{c}}$, Cynthia de Wit ${ }^{\mathrm{d}}$,

13 Line Småstuen Haug ${ }^{\mathrm{e}}$, Adrian C. Williams ${ }^{\mathrm{f}}$, Jörgen Magnér ${ }^{\mathrm{c}}$, Chris D. Collins ${ }^{\mathrm{a} * *}$

$14{ }^{a}$ Soil Research Centre, University of Reading, Reading, RG6 6DW, UK

$15{ }^{\mathrm{b}}$ RECETOX, Masaryk University, Kamenice 753/5, pavilion A29, 62500 Brno, Czech

16 Republic

17 c IVL Swedish Environmental Research Institute, SE-100 31, Stockholm, Sweden

$18{ }^{\mathrm{d}}$ Department of Environmental Science and Analytical Chemistry (ACES), Stockholm

19 University, SE-106 91, Stockholm, Sweden

$20{ }^{\mathrm{e}}$ Norwegian Institute of Public Health (NIPH), P.O. Box 4404, Nydalen, 0403 Oslo, Norway

$21{ }^{\mathrm{f}}$ School of Pharmacy, University of Reading, Whiteknights, Reading, UK

22

23 * - Corresponding authors: Katerina Kademoglou: kademoglou@ recetox.muni.cz \&

24 Katerina.kademoglou@gmail.com ; **Chris Collins: c.d.collins@ reading.ac.uk 


\section{$26 \quad$ Abstract}

27 Phthalate esters (PEs) are plasticiser additives imparting durability, elasticity and flexibility

28 to consumer products. The low migration stability of PEs along with their ubiquitous

29 character and adverse health effects to humans and especially children has resulted in their

30 classification as major indoor contaminants. This study assesses inhalation exposure to PEs

31 via indoor dust using an in vitro inhalation bioaccessibility test (i.e. uptake) for of dimethyl

32 phthalate (DMP), diethyl phthalate (DEP) and di-(2-ethylhexyl) phthalate (DEHP) and the

33 alternative non phthalate plasticisers bis(2-ethylhexyl) terephthalate (DEHT) and

34 cyclohexane-1,2-dicarboxylic acid diisononyl ester (DINCH), exposure. Using artificial lung

35 fluids, which mimicktwo distinctively different pulmonary environments, namely artificial

36 lysosomal fluid ( $\mathrm{ALF}, \mathrm{pH}=4.5$ ) representing the fluid that inhaled particles would contact

37 after phagocytosis by alveolar and interstitial macrophages within the lung and Gamble's

38 solution $(\mathrm{pH}=7.4)$, the fluid for deep dust deposition within the pulmonary environment.

39 Low molecular weight (MW) PEs such as DMP and DEP were highly bioaccessible (> $75 \%$ )

40 in both artificial pulmonary media, whereas highly hydrophobic compounds such as DEHP,

41 DINCH and DEHT were $<5 \%$ bioaccessible via the lung. Our findings show that the in vitro

42 pulmonary uptake of PEs is primarily governed by their hydrophobicity and water solubility,

43 highlighting thus the need for the establishment of a unified and biologically relevant

44 inhalation bioaccessibility test format, employed within the risk assessment framework for

45 volatile and semi-volatile organic pollutants.

46

47 Keywords: bioaccessibility, inhalation, phthalate esters, indoor dust, artificial lysosomal

48 fluid, DINCH

49 


\section{Introduction}

51 Phthalate esters (PEs) are plasticiser additives enhancing durability, elasticity and flexibility in consumer and polymeric products ${ }^{1}$. Low molecular weight (LMW) PEs such as dimethyl phthalate (DMP) and diethyl phthalate (DEP) are added as synthetic stabilisers to industrial solvents and personal care products they are also used as colouring or fragrance additives ${ }^{2,3}$. High MW (HMW) PEs such as di-(2-ethylhexyl) phthalate (DEHP) and di-iso-nonyl phthalate (DiNP) are primarily used in polyvinyl chloride (PVC) products including floor polishing, wall coatings, children's toys, medical products and food packaging ${ }^{4-6}$. Their low migration stability and vapour pressure influence PE release to the indoor environment, resulting in their classification as major indoor organic contaminants ${ }^{7,8}$. Consequently, considerably high levels of PEs have been found in indoor dust worldwide ${ }^{5,9-13}$.

Human exposure to PEs in the indoor environment is a phenomenon of growing concern due to the potentially adverse health effects of PEs such as DEHP, di-n-butyl phthalate (DnBP) and di-iso-butyl phthalate (DiBP) in adults, such as disrupted endocrine and thyroid homeostasis, reduced fertility and reproduction ${ }^{3,14,15}$. Hence, the US and the EU have partly restricted the use of DiBP, DnBP, and DEHP in toys and childcare products ${ }^{16,17}$. Such actions paved the way for the introduction of less toxic, non-phthalate substitutes (i.e. alternative plasticisers) in consumer products in the early 2000s, such as di-isononylcyclohexane-1,2-dicarboxylate (DINCH; DEHP and DiNP replacement) and bis(2ethylhexyl) terephthalate (DEHT), a structural isomer of DEHP ${ }^{18-21}$. However, due to their dominant use and rapid substitution, considerable levels of DINCH and DEHT have been reported in the indoor environment, raising concerns about their potential effects on humans $22-25$.

Due to their critical and vulnerable developmental status, pre and postnatal children's exposure to PEs via indoor dust and PVC materials has been linked with chronic respiratory problems such as allergies, asthma, bronchial hyperactivity and inflammation, as well as neurodevelopmental disorders manifesting in adulthood ${ }^{26-31}$. Franken et al. (2017) reported the high occurrence of asthma in Belgian teenagers (especially girls) associated with high DEHP and DnBP exposure ${ }^{32}$. DEHT and DINCH administration to rodents revealed no signs of DEHP-like toxicity ${ }^{33-35}$. However, DINCH in utero exposure has been associated with

80 signs of impaired liver metabolism and premature testicular aging such as decreased 81 testosterone secretion, physical changes in seminal glands and testicular atrophy in rats and 
their young offspring ${ }^{36}$. Thus, the debate regarding the safety of alternative plasticisers is ongoing especially during early-life exposure.

Physiologically-based extraction tests (PBET) have been employed to assess the oral bioaccessibility (i.e. uptake) of PEs via dust ingestion ${ }^{37-39}$. PE gut bioaccessibility decreased as $\log \mathrm{K}_{\mathrm{ow}}$ increased; LMW PEs such as DMP and DEP were found to be $32 \%$ and $26 \%$ bioaccessible, respectively, while DEHP was only $10 \%$ bioaccessible via the gut ${ }^{38}$. In a comparative study between different dust size fractions and oral bioaccessibility, Wang et al. (2013) reported the highest gut uptake for LMW PEs in $<63 \mu \mathrm{m}$ size fraction, compared to particles $>63 \mu \mathrm{m}^{39}$. Dermal absorption of DEP and DnBP directly from air has been proposed by Weschler et $\mathrm{al}^{40}$. Since no studies exist regarding the inhalation bioaccessibility of organic pollutants, this calls for their development ${ }^{41}$.

This is the first study we are aware of quantifying the inhalation bioaccessibility of PEs and alternative plasticisers employing two artificial lung fluids, mimicking two distinctively different interstitial lung conditions. Artificial pulmonary fluids have been previously employed in inhalation bioaccessibility studies of water-soluble metals and nanoparticles ${ }^{42-}$ 46. Artificial lysosomal fluid (ALF, $\mathrm{pH}=4.5$ ) represents the fluid which inhaled particles come into contact with after phagocytosis by alveolar and interstitial macrophages within the lung. Gamble's solution (GMB, $\mathrm{pH}=7.4$ ) is a surrogate fluid for deep dust deposition within the interstitial fluid of the lung ${ }^{43,46}$. The objectives of the present study are to evaluate the in vitro inhalation bioaccessibility of PEs, DINCH and DEHT present in indoor dust by employing two different artificial pulmonary fluids, i.e. Gamble's solution and ALF representing the healthy and inflammatory status of the tracheobronchial environment, respectively and to assess possible factors influencing inhalation bioaccessibility of PEs, DINCH and DEHT.

\section{Material and methods}

Sampling and dust particle properties

Details on the A-TEAM sampling protocols are given elsewhere ${ }^{47}$. Pre-existing vacuum cleaner dust samples $(\mathrm{N}=10)$ were passed through a methanol-washed, metallic sieve $(<63$ $\mu \mathrm{m})$ with respect to the inhalable aerodynamic particle cut off convention according to the International Organization for Standardization (ISO) ${ }^{48}$. Specific surface area and dust particle size were determined by laser diffraction spectroscopy (Mastersizer 3000, Malvern Ltd., 
113 UK), while total carbon (TC \%) and nitrogen (TN \%) contents were determined by Thermo

114 Flash 2000 and organic matter content (OMC \%) was determined by loss-on-ignition (LOI)

115 as described elsewhere ${ }^{49}$.

116 Dust extraction and clean-up

117 Details of the indoor dust extraction have been published previously ${ }^{24,50}$. Briefly, $100 \mathrm{mg}$ of

118 dust $(<63 \mu \mathrm{m})$ were extracted with $10 \mathrm{~mL}$ acetone: $\mathrm{n}$-hexane $(1: 1 \mathrm{v} / \mathrm{v})$ using microwave-

119 assisted extraction (MAE) under controlled pressure and temperature. Prior to extraction, 400

120 ng ISTD mix prepared in n-hexane (DMP- $\mathrm{d}_{4}$, DnBP- $\mathrm{d}_{4}$ and DEHP- $\left.\mathrm{d}_{4}\right)$ were spiked into all

121 samples. The dust extracts were concentrated to $0.5 \mathrm{ml}$ under a gentle nitrogen $\left(\mathrm{N}_{2}\right)$ stream

122 which was filtrated through a glass Pasteur pipette tip containing charcoal in order to

123 eliminate any traces of external contamination and the solvent was exchanged to n-hexane.

124 This solution was loaded onto an ENVI-Florisil cartridge (500 mg / $3 \mathrm{~mL}$, Biotage Isolute,

125 Uppsala, Sweden) and $9 \mathrm{~mL}$ of $\mathrm{n}$-hexane were added as a cleaning elution step. During the

126 second elution, all target analytes were eluted using the $9 \mathrm{~mL}$ acetone: $\mathrm{n}$-hexane $(1: 1)$ and the

127 resulting eluate was concentrated to $1 \mathrm{ml}$ with a gentle $\mathrm{N}_{2}$ flow at room temperature, filtered

128 as described above. Finally, all extracts were transferred to GC vials and biphenyl (300 ng)

129 was added as an injection recovery standard prior to GC-MS/MS analysis (Fig SI 1). Further

130 details about instrumental analysis are available in SI.

131 Lung fluid extraction

132 All lung fluid extractions were conducted in duplicate. Both media were freshly prepared 24

$133 \mathrm{~h}$ before the initiation of each test in ultra-pure $\mathrm{H}_{2} \mathrm{O}\left(18.2 \Omega\right.$ ) as described elsewhere ${ }^{43}$ (Table

134 SI 3), $\mathrm{pH}$-adjusted using $\mathrm{HCl} 1 \mathrm{M}$ and $\mathrm{NaOH} 1 \mathrm{M}$, stored at $4^{\circ} \mathrm{C}$ and were checked for

135 background phthalate contamination prior use. According to Boisa et al (2014), the

136 experimental volume for simulated lung fluid extraction tests should be equal to $20 \mathrm{~mL}$,

137 given the pulmonary fluid volume capacity of healthy non-smoking adults $(0.3 \mathrm{~mL} / \mathrm{kg} ; 70$

$138 \mathrm{~kg}$ body mass $)^{42}$. In order to maintain 1:100 solid-to-liquid (S/L) ratio between the incubated

139 matrix and the pulmonary fluid, $0.2 \mathrm{~g}$ of indoor dust $(<63 \mu \mathrm{m})$ were combined with $20 \mathrm{~mL}$ of

140 each artificial lung fluid separately, as suggested by Schaider et al ${ }^{51}$. All samples were

141 covered on top with oven-baked aluminium foil to avoid background phthalate

142 contamination, followed by continuous incubation inside a thermostatic chamber ( $60 \mathrm{rpm} ; 37$

$143{ }^{\circ} \mathrm{C}$ ) for $96 \mathrm{~h}$, a time point relevant to the human alveolar clearance capacity ${ }^{45,52}$. After $96 \mathrm{~h}$,

144 the samples were separated by centrifugation (1500 rpm; $3 \mathrm{~min}$ ) and the lung supernatants 
were subjected to liquid-liquid extraction (LLE) using $7 \mathrm{~mL}$ Hexane: MTBE 3:1 twice, while ultrasonication-assisted extraction was employed for the residual dusts twice for 10 min using

$1477 \mathrm{~mL}$ of Acetone: Hexane 1:1. Prior to all extractions, all samples were spiked with $400 \mathrm{ng}$ 148 ISTD mix prepared in n-hexane (DMP- $\mathrm{d}_{4}$, DnBP- $_{4}$ and DEHP- $\left.\mathrm{d}_{4}\right)$. To avoid any water 149 residue and remove any gel-like emulsion formulated during LLE, sufficient amount of oven150 baked $\mathrm{Na}_{2} \mathrm{SO}_{4}$ (powder) was added to all extracts, followed by 1 min vortexing and organic 151 phase collection after centrifugation (1500 rpm; $3 \mathrm{~min}$ ). All extracts were combined, solvent was exchanged to $\mathrm{n}$-hexane and concentrated to $1 \mathrm{ml}$ under a gentle $\mathrm{N}_{2}$ stream at room temperature, filtered as described above. The residual dust extracts were subjected for cleanup through ENVI-Florisil SPE cartridge (500 mg / $3 \mathrm{~mL}$, Biotage Isolute, Uppsala, Sweden), similarly to the dust extraction procedure described above. Briefly, the residual dust extracts were loaded onto the Florisil ${ }^{\circledR}$ columns, the first hexane eluate was discarded, while the second eluate was collected using $9 \mathrm{~mL}$ of MTBE. The resulting eluate was concentrated to 1 $\mathrm{ml}$ under a gentle $\mathrm{N}_{2}$ flow at room temperature, filtered as described above. Finally, all extracts were transferred to oven-baked GC vials and biphenyl (300 ng) was added as an injection recovery standard prior to GC-MS/MS analysis (Fig SI 2).

Data analysis

Inhalation bioaccessibility (IBAF) was determined using Eq. 1, where mass phthalate (lung supernatant) is set as the phthalate mass (ng) determined in the lung supernatant of the in vitro pulmonary system and mass phthalate (dust residual) is the mass (ng) determined in the dust residual collected after the $96 \mathrm{~h}$-incubation of the in vitro pulmonary system which is considered as the non-bioaccessible fraction.

$\mathrm{IBAF} \%$

$$
=\frac{\text { mass phthalate }\left(\begin{array}{c}
\text { lung } \\
\text { supernatant }
\end{array}\right)}{\text { mass phthalate (lung supernatant) }+ \text { mass phthalate }(\text { dust residual) }} \times 100
$$

170 GraphPad Prism ${ }^{\circledR}$ version 7.00 for Windows, (GraphPad Software, La Jolla CA, USA) was used for statistical analysis. Prior to statistical analysis, all data were checked for normality using the Shapiro-Wilk test and not all data passed the normality test. All data were arc-sine transformed, as this mathematical transformation is necessary for statistical analysis of results set in percentages in order to equalise variances among treatments ${ }^{53}$. Ordinary two-way ANOVA (Uncorrected Fisher's test, $\mathrm{p}<0.05$ ) was performed to assess statistically significant 
176 differences of target analytes between both pulmonary fluids. Spearman's correlation

$177(\mathrm{p}<0.05)$ was employed to assess statistical dependence and correlation between artificial

178 lung fluids and the physicochemical properties of all target analytes.

179 Quality assurance and quality control

180 The methods were evaluated using SRM 2585 as QC sample during dust $(n=5)$ and lung fluid

$181(\mathrm{n}=4)$ extractions, respectively. Oven-baked, uncontaminated sand was used as a procedural

182 blank during dust extractions; four blank lung fluid samples with no added matrix (two for

183 each lung fluid) were sequentially incubated and analysed as procedural blanks. The results

184 were blank-corrected for all target analytes by subtraction of the mean blank values from the

185 raw target analytes values (expressed in $\mathrm{ng} \mathrm{g}^{-1}$ ) according to Abdhalah and Covaci ${ }^{54}$.

186 Extraction efficiency for all target analytes ranged from $70-120 \%$ for both lung fluids

187 respectively (Table SI 6). Method limits of detection (mLOD) were calculated as three times

188 the standard deviation of the lung fluid blanks (Table SI 7).

\section{Results and discussion}

190 PEs and alternative plasticisers in indoor dust

191 Apart from DEHT, levels of PEs and DINCH from floor $(\mathrm{N}=61)$ and vacuum cleaner dust

$192(\mathrm{~N}=58)$ from the ATEAM cohort have been previously reported ${ }^{23}$ and were of the same order

193 of magnitude as reported here ( $\mathrm{N}=10$; SI Table xxx). Besides the smaller dust particle size

194 used in this study compared to Giovanoulis et al. ${ }^{23}$ ( $<63 \mu \mathrm{m}$ and $<500 \mu \mathrm{m}$, respectively), the

195 median values for all target analytes were marginally different apart from DINCH (this study:

$19617.06 \mu \mathrm{g} \mathrm{g}^{-1}$, Giovanoulis et al.: $\left.32.82 \mu \mathrm{g} \mathrm{g}^{-1} ; \mathrm{p}<0.05\right)$. Substantial differences between the

197 maximum values of two studies were also found, e.g. DEP (this study: $54.2 \mu \mathrm{g} \mathrm{g}^{-1}$,

198 Giovanoulis et al: $240 \mu \mathrm{g} \mathrm{g}^{-1}$ ) or DiNP (this study: $2470 \mu \mathrm{g} \mathrm{g}^{-1}$, Giovanoulis et al: $1490 \mu \mathrm{g} \mathrm{g}^{-}$

$199{ }^{1}$ ). These findings can be attributed to a) differences in sample size assessed and b)

200 differences in particle size cut off and specific surface area which are likely to influence a

201 pollutant's concentration in dust ${ }^{39,55}$. However, the aim of the present study is primarily to

202 assess the inhalation bioacceessibility of PEs and their alternatives plasticisers, rather than 203 report on their levels in dust. 
205 This is the first study on the in vitro inhalation bioaccessibility of PEs and alternative plasticisers via indoor dust. Inhalation bioaccessibility for DMP and DEP exceeded $70 \%$ in both pulmonary media (Fig. 1). Statistical comparison of IBAF between the two pulmonary media did not reveal any statistically significant differences for any target analyte regarding the fluids' $\mathrm{pH}(\mathrm{pH}$ Gamble's = 7.4; $\mathrm{pH}$ ALF = 4.5) and composition, apart from DMP ( $\mathrm{p}=0.017$ ) with $71 \%$ and $82 \%$ IBAF for Gamble's solution and ALF, respectively. DEP was also readily absorbed with $76 \%$ and $75 \%$ IBAF in Gamble's solution and ALF, respectively ( $>0.05$ ), showing thus that inhalation is an important route of exposure for LMW PEs.

213 Gamble's solution is representative of the interstitial fluid of the deep lung area and ALF is

214 representative of the more acidic environment following phagocytosis by alveolar and

215 interstitial macrophages within the lung ${ }^{42,43}$. Hence, the inhaled dust particles would not have

216 to be phagocytised before a considerable uptake of plasticisers occurs, with the exception of

217 DMP.

218 Similarly to gut bioaccessibility which is partly governed by a pollutant's physico-chemical properties including MW and $\log \mathrm{K}_{\mathrm{ow}}{ }^{56,57}$, inhalation bioaccessibility of PEs decreased against the increasing trend in MW and $\log$ Kow (> 4). DiBP pulmonary uptake was $15.5 \%$ and $12 \%$, in Gamble's solution and ALF, respectively, whereas DnBP and HMW PEs were $10 \%$ and $<5 \%$ bioaccessible in both media, including DEHP and its alternatives, DEHT and DINCH (Fig 1). Such findings endorse ingestion (food or dust) and dermal uptake as the predominant exposure routes for medium and HMW PEs, strongly influenced by their hydrophobic character and low water solubility ${ }^{6,23,38}$. However, no consensus exists regarding pulmonary media composition for inhalation bioaccessibility studies of organics. Employing modified media formulations with the addition of biologically relevant pulmonary surfactants such as albumin, mucin and dipalmitoylphosphatidylcholine (DPCC) have been proposed $^{41,42,58}$; the case of DPCC makes biological sense and it should be thus systematically investigated along with other test parameters including $\mathrm{S} / \mathrm{L}$, incubation duration and particle size cut off ${ }^{41,59}$, aiming towards a unified approach similarly to gut bioaccessibility ${ }^{56}$.

233 Method performance using SRM 2585

Method performance was assessed using SRM 2585, since the pulmonary media used here were initially designed for nanoparticle and trace element inhalation bioaccessibility 
studies ${ }^{43,45,60}$. IBAF > $75 \%$ was found for LMW PEs, while DEHP and DiNP were the least bioaccessible (IBAF < $5 \%$ ) as highly hydrophobic compounds (Table 1), following a comparable pattern to the Norwegian house dust IBAF results. The SRM 2585 batch purchased in our study was prepared using a pool of dust samples collected during mid to late 1990s. Thus, DINCH and DPHP were not detected, since they were introduced in the market after $2000^{18,61}$.

In this study we propose an in vitro method regarding the inhalation bioaccessibility of PEs and their alternatives via indoor dust. Low MW PEs such as DMP and DEP were highly bioaccessible in both artificial pulmonary media (> $75 \%)$, regardless of the medium's $\mathrm{pH}$ and composition. Unlike DEP which presented similar pulmonary uptake in both media, DMP was more readily absorbed through ALF than Gamble's solution. HMW PEs along with DEHP alternatives, DEHT and DINCH did not exceed $5 \%$ pulmonary uptake. Therefore, inhalation is a considerable route of exposure for LMW and less hydrophobic PEs. The lung uptake potential for compounds with comparable physico-chemical properties, e.g. LMW polycyclic aromatic hydrocarbons (PAHs) or organophosphates (PFRs) should be further assessed. Our results show that inhalation bioaccessibility of organic pollutants is primarily governed by hydrophobicity and water solubility. Future research should be targeted towards a unified and biologically relevant in vitro pulmonary uptake test for organics relevant to dust deposition in the lung, human lung function and inflammation in vivo. Finally, animal studies are more representative of the in vivo situation, marking them as necessary for the validation of in vitro inhalation bioaccessibility tests.

\section{Conflict of interest}

The authors declare no conflict of interest.

\section{Acknowledgments}

260 The research leading to these results has received funding from the European Union Seventh

261 Framework Programme FP7/2007-2013 under grant agreement n 316665 (A-TEAM

262 project). Katerina Kademoglou and George Giovanoulis would like to thank Dr. Yolanda

263 Hedberg from KTH (Sweden) for her help and useful guidance during the experimental

264 design. We acknowledge Dr. Eleni Papadopoulou and Dr. Juan Antonio Padilla Sanchez from

265 NIPH (Norway) for their help during the ATEAM sampling campaign. The writing up of this 
manuscript was supported by the National Sustainability Project of the Czech Ministry of

267 Education (project number here) and the RECETOX Research Infrastructure (LM2015051 and CZ.02.1.01/0.0/0.0/16_013/0001761)._Katerina Kademoglou would like to thank Dr.

269 Shovonal Roy (UoR) for his useful comments on the statistical analysis and acknowledge the

270 financial support from the Mediterranean Scientific Association of Environmental Protection

271 (MESAEP) during her PhD studies by means of the Emmanuel Lahaniatis award for young 272 scientists.

\section{Artwork and tables}

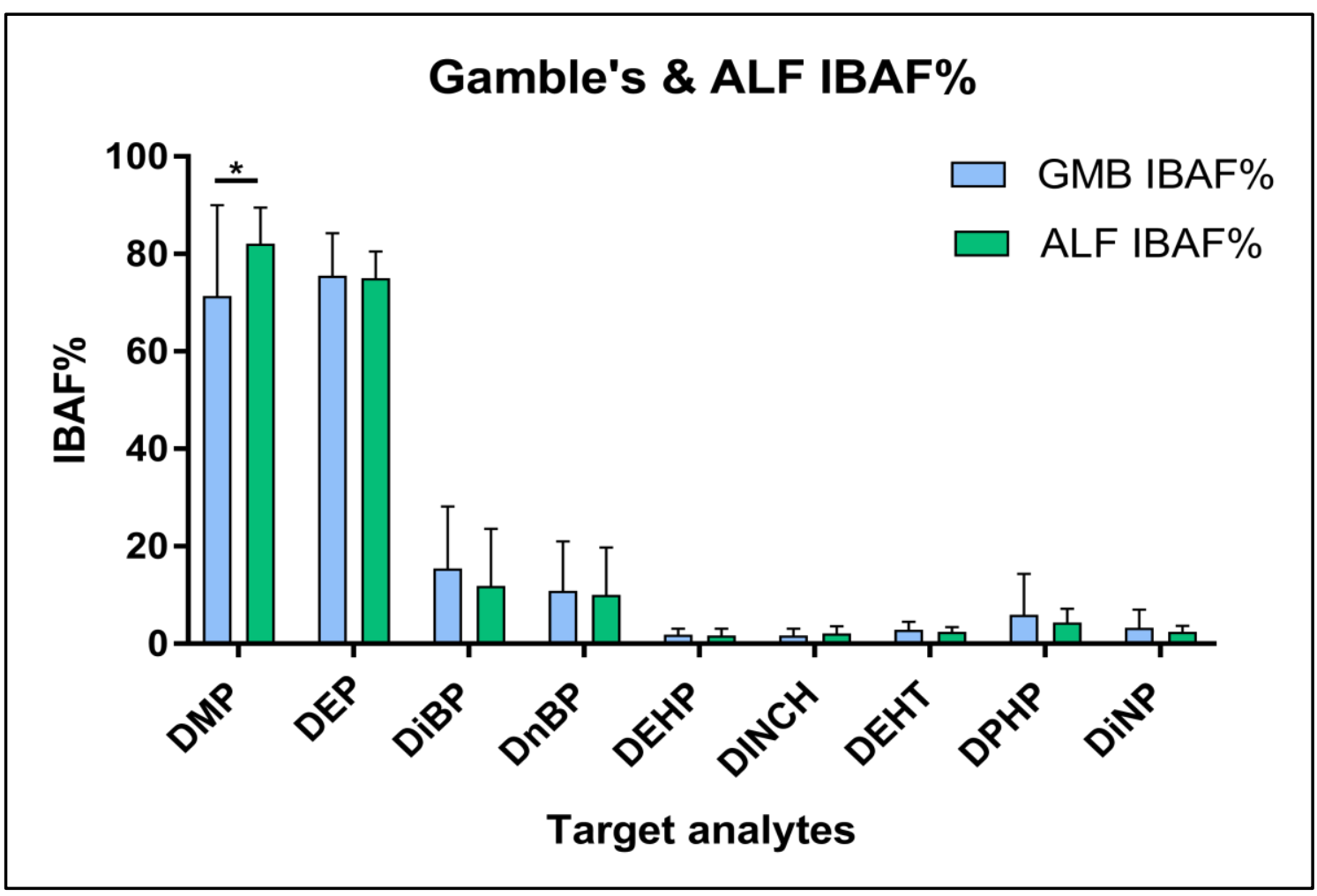

275 Figure 1 - In vitro inhalation bioaccessibility (IBAF\%) of phthalate esters and alternative

276 plasticisers present in indoor dust samples $(\mathrm{N}=10)$, using two different simulated lung fluids, namely Gamble's solution (GMB) and artificial lysosomal fluid (ALF). Statistically

278 significant differences shown here $(* ; p<0.05)$. Bar charts represent average values in

279 duplicates. Error bars represent 1 STDEV.

280 Table 1 - Lung fluid method performance using SRM $2585(\mathrm{n}=4)$ for Gamble's solution and 281 artificial lysosomal fluid (ALF)

\begin{tabular}{|c|c|c|c|c|}
\hline $\begin{array}{c}\text { Target } \\
\text { analytes }^{\dagger}\end{array}$ & $\begin{array}{c}\text { Gamble's } \\
\text { IBAF\% } \\
(\mathrm{n}=2)\end{array}$ & STDEV & $\begin{array}{c}\text { ALF IBAF\% } \\
(\mathrm{n}=2)\end{array}$ & STDEV \\
\hline
\end{tabular}




\begin{tabular}{|c|c|c|c|c|}
\hline DMP & 89.9 & 1.8 & 89.5 & 0.3 \\
\hline DEP & 80.7 & 1.2 & 73.7 & 1.0 \\
\hline DiBP & 17.6 & 2.7 & 8.0 & 0.6 \\
\hline DnBP & 9.8 & 1.3 & 6.2 & 0.5 \\
\hline BzBP & 18.5 & 3.6 & 13.2 & 0.6 \\
\hline DEHP & 3.1 & 1.6 & 2.0 & 0.2 \\
\hline DEHT & 4.9 & 1.6 & 4.6 & 0.6 \\
\hline DiNP & 3.9 & 1.0 & 3.5 & 0.3 \\
\hline
\end{tabular}

282

${ }^{\dagger}$ DINCH and DPHP not present in SRM 2585

283 Table 2-Spearman's correlation between inhalation bioaccessibility (IBAF) in Gamble's

284 solution (GMB) and artificial lysosomal fluid (ALF) and the physicochemical properties of

285 plasticisers studied here

\begin{tabular}{|l|l|l|l|l|}
\hline & \multicolumn{2}{l|}{ GMB IBAF } & ALF IBAF \\
\hline $\begin{array}{l}\text { Physico-chemical } \\
\text { properties }\end{array}$ & Spearman's $\rho$ & p value & Spearman's $\rho$ & p value \\
\hline MW & -0.561 & 0.096 & -0.561 & 0.096 \\
\hline Log Kow & -0.705 & $0.027^{*}$ & -0.705 & $0.027^{*}$ \\
\hline Log Koa & -0.588 & 0.081 & -0.624 & 0.060 \\
\hline Vapour pressure & -0.535 & 0.115 & -0.559 & 0.098 \\
\hline Water solubility & 0.661 & $0.044^{*}$ & 0.636 & 0.054 \\
\hline
\end{tabular}

286 *levels of statistical significance: $\mathrm{p}<0.05$

$287 \uparrow$ Physicochemical properties of plasticisers studied here can be found at Table SI xxx 


\section{References}

1. Wilkes, C. E., Summers, J. W., Daniels, C. A. \& Berard, Mark, T. PVC Handbook. (Hanser Gardner Pubns, 2005).

2. Hauser, R., Duty, S., Godfrey-Bailey, L. \& Calafat, A. M. Medications as a source of human exposure to phthalates. Environ. Health Perspect. 112, 751-753 (2004).

3. Heudorf, U., Mersch-Sundermann, V. \& Angerer, J. Phthalates: Toxicology and exposure. Int. J. Hyg. Environ. Health 210, 623-634 (2007).

4. Bernard, L. et al. Migration of plasticizers from PVC medical devices: Development of an infusion model. Int. J. Pharm. 494, 136-145 (2015).

5. Dodson, R. E., Camann, D. E., Morello-Frosch, R., Brody, J. G. \& Rudel, R. A. Semivolatile Organic Compounds in Homes: Strategies for Efficient and Systematic Exposure Measurement Based on Empirical and Theoretical Factors. Environ. Sci. Technol. 49, 113-122 (2015).

6. Wormuth, M., Scheringer, M., Vollenweider, M. \& Hungerbühler, K. What Are the Sources of Exposure to Eight Frequently Used Phthalic Acid Esters in Europeans? Risk Anal. 26, 803-824 (2006).

7. Uhde, E., Bednarek, M., Fuhrmann, F. \& Salthammer*, T. Phthalic Esters in the Indoor Environment - Test Chamber Studies on PVC-Coated Wallcoverings. Indoor Air 11, 150-155 (2001).

8. Zhang, J. (Jim) \& Smith, K. R. Indoor air pollution: a global health concern. Br. Med. Bull. 68, 209-225 (2003). 
9. Albar, H. M. S. A. et al. Phthalate esters in settled dust of different indoor microenvironments; source of non-dietary human exposure. Microchem. J. 132, 227-232 (2017).

10. Bergh, C., Torgrip, R., Emenius, G. \& Östman, C. Organophosphate and phthalate esters in air and settled dust - a multi-location indoor study. Indoor Air 21, 67-76 (2011).

11. Kubwabo, C. et al. Analysis of selected phthalates in Canadian indoor dust collected using household vacuum and standardized sampling techniques. Indoor Air 23, 506-514 (2013).

12. Langer, S. et al. Phthalate and PAH concentrations in dust collected from Danish homes and daycare centers. Atmos. Environ. 44, 2294-2301 (2010).

13. Luongo, G. \& Östman, C. Organophosphate and phthalate esters in settled dust from apartment buildings in Stockholm. Indoor Air 26, 414-425 (2016).

14. Hauser, R. \& Calafat, A. M. Phthalates and Human Health. Occup. Environ. Med. 62, 806-818 (2005).

15. Matsumoto, M., Hirata-Koizumi, M. \& Ema, M. Potential adverse effects of phthalic acid esters on human health: A review of recent studies on reproduction. Regul. Toxicol. Pharmacol. 50, 37-49 (2008).

16. Consumer Product Safety Commission. The Consumer Product Safety Improvement Act (CPSIA) - Products Containing Certain Phthalates. CPSC.gov (2012). Available at: https://www.cpsc.gov/Regulations-Laws--Standards/Statutes/The-Consumer-ProductSafety-Improvement-Act. (Accessed: 14th February 2018) 
17. European Comission. Directive 2005/84/EC of the European Parliament relating to restrictions on the marketing and use of certain dangerous substances and preparations (phthalates in toys and childcare articles) - 2005. (2005).

18. Bui, T. T. et al. Human exposure, hazard and risk of alternative plasticizers to phthalate esters. Sci. Total Environ. 541, 451-467 (2016).

19. Crespo, J. E., Balart, R., Sanchez, L. \& López, J. Substitution of di(2-ethylhexyl) phthalate by di(isononyl) cyclohexane-1,2-dicarboxylate as a plasticizer for industrial vinyl plastisol formulations. J. Appl. Polym. Sci. 104, 1215-1220 (2007).

20. EFSA. EFSA opinion of the Scientific Panel on food additives, flavourings, processing aids and materials in contact with food (AFC). (2006).

21. European Comission. Scientific Committee on Emerging and Newly-Identified Health Risks (SCENIHR) - Opinion on the safety of medical devices containing DEHP plasticized PVC or other plasticizers on neonates and other groups possibly at risk (2015 update). (2015). doi:10.2772/45179

22. Fromme, H. et al. Non-phthalate plasticizers in German daycare centers and human biomonitoring of DINCH metabolites in children attending the centers (LUPE 3). Int. J. Hyg. Environ. Health 219, 33-39 (2016).

23. Giovanoulis, G. et al. Multi-pathway human exposure assessment of phthalate esters and DINCH. Environ. Int. 112, 115-126 (2018).

24. Larsson, K. et al. Phthalates, non-phthalate plasticizers and bisphenols in Swedish preschool dust in relation to children's exposure. Environ. Int. 102, 114-124 (2017).

25. Nagorka, R., Conrad, A., Scheller, C., Süssenbach, B. \& Moriske, H.-J. Diisononyl 1,2cyclohexanedicarboxylic acid (DINCH) and Di(2-ethylhexyl) terephthalate (DEHT) in 
indoor dust samples: concentration and analytical problems. Int. J. Hyg. Environ. Health 214, 26-35 (2011).

26. Bellinger, D. C. Prenatal Exposures to Environmental Chemicals and Children's Neurodevelopment: An Update. Saf. Health Work 4, 1-11 (2013).

27. Bornehag, C. G. \& Nanberg, E. Phthalate exposure and asthma in children. Int. J. Androl. 33, 333-345 (2010).

28. Fromme, H. et al. Phthalates in German daycare centers: Occurrence in air and dust and the excretion of their metabolites by children (LUPE 3). Environ. Int. 61, 64-72 (2013).

29. Hsu, N.-Y. et al. Predicted risk of childhood allergy, asthma, and reported symptoms using measured phthalate exposure in dust and urine. Indoor Air 22, 186-199 (2012).

30. Jaakkola, J. J. K. \& Knight, T. L. The Role of Exposure to Phthalates from Polyvinyl Chloride Products in the Development of Asthma and Allergies: A Systematic Review and Meta-analysis. Environ. Health Perspect. 116, 845-853 (2008).

31. Lin, L.-Y. et al. Childhood exposure to phthalates and pulmonary function. Sci. Total Environ. 615, 1282-1289 (2018).

32. Franken, C. et al. Phthalate-induced oxidative stress and association with asthma-related airway inflammation in adolescents. Int. J. Hyg. Environ. Health 220, 468-477 (2017).

33. Campioli, E., Duong, T. B., Deschamps, F. \& Papadopoulos, V. Cyclohexane-1,2dicarboxylic acid diisononyl ester and metabolite effects on rat epididymal stromal vascular fraction differentiation of adipose tissue. Environ. Res. 140, 145-156 (2015).

34. David, R. M., White, R. D., Larson, M. J., Herman, J. K. \& Otter, R. Toxicity of Hexamoll® DINCH® following intravenous administration. Toxicol. Lett. 238, 100-109 (2015). 
35. Wirnitzer, U., Rickenbacher, U., Katerkamp, A. \& Schachtrupp, A. Systemic toxicity of di-2-ethylhexyl terephthalate (DEHT) in rodents following four weeks of intravenous exposure. Toxicol. Lett. 205, 8-14 (2011).

36. Campioli, E., Lee, S., Lau, M., Marques, L. \& Papadopoulos, V. Effect of prenatal DINCH plasticizer exposure on rat offspring testicular function and metabolism. Sci. Rep. 7, 11072 (2017).

37. He, R. et al. Organophosphorus flame retardants and phthalate esters in indoor dust from different microenvironments: Bioaccessibility and risk assessment. Chemosphere 150, 528-535 (2016).

38. Kang, Y., Man, Y. B., Cheung, K. C. \& Wong, M. H. Risk Assessment of Human Exposure to Bioaccessible Phthalate Esters via Indoor Dust around the Pearl River Delta. Environ. Sci. Technol. 46, 8422-8430 (2012).

39. Wang, W. et al. Size fraction effect on phthalate esters accumulation, bioaccessibility and in vitro cytotoxicity of indoor/outdoor dust, and risk assessment of human exposure. $J$. Hazard. Mater. 261, 753-762 (2013).

40. Weschler, C. J. et al. Transdermal Uptake of Diethyl Phthalate and Di(n-butyl) Phthalate Directly from Air: Experimental Verification. Environ. Health Perspect. 123, 928-934 (2015).

41. Wei, W. et al. Bioaccessibility and bioavailability of environmental semi-volatile organic compounds via inhalation: A review of methods and models. Environ. Int. 113, 202-213 (2018).

42. Boisa, N. et al. Development and application of an inhalation bioaccessibility method (IBM) for lead in the PM10 size fraction of soil. Environ. Int. 70, 132-142 (2014). 
43. Hedberg, Y., Gustafsson, J., Karlsson, H. L., Möller, L. \& Wallinder, I. O. Bioaccessibility, bioavailability and toxicity of commercially relevant iron- and chromium-based particles: in vitro studies with an inhalation perspective. Part. Fibre Toxicol. 7, 23 (2010).

44. Li, S.-W. et al. Influence of pollution control on lead inhalation bioaccessibility in PM2.5: A case study of 2014 Youth Olympic Games in Nanjing. Environ. Int. 94, 69-75 (2016).

45. Wragg, J. \& Klinck, B. The bioaccessibility of lead from Welsh mine waste using a respiratory uptake test. J. Environ. Sci. Health Part A 42, 1223-1231 (2007).

46. Dean, J. R., Elom, N. I. \& Entwistle, J. A. Use of simulated epithelial lung fluid in assessing the human health risk of $\mathrm{Pb}$ in urban street dust. Sci. Total Environ. 579, 387395 (2017).

47. Papadopoulou, E. et al. Sampling strategy for estimating human exposure pathways to consumer chemicals. Emerg. Contam. 2, 26-36 (2016).

48. ISO. ISO 7708:1995 - Air quality -- Particle size fraction definitions for health-related sampling. (1995).

49. Yu, Y.-X. et al. Concentrations and seasonal variations of polybrominated diphenyl ethers (PBDEs) in in- and out-house dust and human daily intake via dust ingestion corrected with bioaccessibility of PBDEs. Environ. Int. 42, 124-131 (2012).

50. Bergh, C., Luongo, G., Wise, S. \& Östman, C. Organophosphate and phthalate esters in standard reference material 2585 organic contaminants in house dust. Anal. Bioanal.

Chem. 402, 51-59 (2012). 
51. Schaider, L. A., Senn, D. B., Brabander, D. J., McCarthy, K. D. \& Shine, J. P.

Characterization of Zinc, Lead, and Cadmium in Mine Waste: Implications for Transport, Exposure, and Bioavailability. Environ. Sci. Technol. 41, 4164-4171 (2007).

52. Lindström, M., Falk, R., Hjelte, L., Philipson, K. \& Svartengren, M. Long-term clearance from small airways in subjects with ciliary dysfunction. Respir. Res. 7, 79 (2006).

53. Sokal, R. R. \& Rohlf, F. J. Biometry: The Principles and Practices of Statistics in Biological Research. (W. H. Freeman, 1994).

54. Abdallah, M. A.-E. \& Covaci, A. Organophosphate Flame Retardants in Indoor Dust from Egypt: Implications for Human Exposure. Environ. Sci. Technol. 48, 4782-4789 (2014).

55. Cao, Z. et al. Distribution Patterns of Brominated, Chlorinated, and Phosphorus Flame Retardants with Particle Size in Indoor and Outdoor Dust and Implications for Human Exposure. Environ. Sci. Technol. (2014). doi:10.1021/es501224b

56. Collins, C. D., Craggs, M., Garcia-Alcega, S., Kademoglou, K. \& Lowe, S. 'Towards a unified approach for the determination of the bioaccessibility of organic pollutants'. Environ. Int. 78, 24-31 (2015).

57. Kademoglou, K., Williams, A. C. \& Collins, C. D. Bioaccessibility of PBDEs present in indoor dust: A novel dialysis membrane method with a Tenax TA® absorption sink. Sci. Total Environ. 621, 1-8 (2018).

58. Pelfrêne, A., Cave, M. R., Wragg, J. \& Douay, F. In Vitro Investigations of Human Bioaccessibility from Reference Materials Using Simulated Lung Fluids. Int. J. Environ. Res. Public. Health 14, 112 (2017).

59. Wiseman, C. L. S. Analytical methods for assessing metal bioaccessibility in airborne particulate matter: A scoping review. Anal. Chim. Acta 877, 9-18 (2015). 
60. Klara Midander, A. de F. Bioaccessibility studies of ferro-chromium alloy particles for a simulated inhalation scenario: a comparative study with the pure metals and stainless steel. Integr. Environ. Assess. Manag. 6, 441-55 (2010).

61. Kozlowski, R. R. \& Storzum, U. Di(2- propylheptyl) phthalate: A new plasticizer choice for PVC compounders. J. Vinyl Addit. Technol. 11, 155-159 (2005).

62. Schreder, E. D., Uding, N. \& La Guardia, M. J. Inhalation a significant exposure route for chlorinated organophosphate flame retardants. Chemosphere 150, 499-504 (2016). 